\title{
Genetic interplay between the transcription factors Sp8 and Emx2 in the patterning of the forebrain
}

\author{
Andreas Zembrzycki ${ }^{\dagger 1,2}$, Gundula Griesel ${ }^{\dagger 1}$, Anastasia Stoykova ${ }^{1,2}$ and \\ Ahmed Mansouri*1,2,3
}

\begin{abstract}
Address: ${ }^{1}$ Max Planck Institute of Biophysical Chemistry, Department of Molecular Cell Biology, Am Fassberg, 37077 Goettingen, Germany, ${ }^{2}$ DFG Center for the Molecular Physiology of the Brain, CMPB, Goettingen, Germany and ${ }^{3}$ Department of Clinical Neurophysiology, University Goettingen, Robert-Koch-Str., 37075 Goettingen, Germany

Email: Andreas Zembrzycki - azembrz@gwdg.de; Gundula Griesel - ggriese@gwdg.de; Anastasia Stoykova - astoyko@gwdg.de; Ahmed Mansouri* - amansou@gwdg.de

* Corresponding author †Equal contributors
\end{abstract}

Published: 30 April 2007

Neural Development 2007, 2:8 doi:10.1186/1749-8104-2-8

Received: 22 February 2007

Accepted: 30 April 2007

This article is available from: http://www.neuraldevelopment.com/content/2/1/8

(C) 2007 Zembrzycki et al.; licensee BioMed Central Ltd.

This is an open access article distributed under the terms of the Creative Commons Attribution License (http://creativecommons.org/licenses/by/2.0), which permits unrestricted use, distribution, and reproduction in any medium, provided the original work is properly cited.

\begin{abstract}
Background: The forebrain consists of multiple structures necessary to achieve elaborate functions. Proper patterning is, therefore, a prerequisite for the generation of optimal functional areas. Only a few factors have been shown to control the genetic networks that establish early forebrain patterning.

Results and conclusion: Using conditional inactivation, we show that the transcription factor Sp8 has an essential role in the molecular and functional patterning of the developing telencephalon along the anteroposterior axis by modulating the expression gradients of Emx2 and Pax6. Moreover, Sp8 is essential for the maintenance of ventral cell identity in the septum and medial ganglionic eminence (MGE). This is probably mediated through a positive regulatory interaction with Fgf8 in the medial wall, and Nkx2.I in the rostral MGE anlage, and independent of SHH and WNT signaling. Furthermore, $S p 8$ is required during corticogenesis to sustain a normal progenitor pool, and to control preplate splitting, as well as the specification of cellular diversity within distinct cortical layers.
\end{abstract}

\section{Background}

The mammalian forebrain, with its components the basal ganglia (subpallium) and cortex (pallium), is a result of advanced evolutionary processes. Although several genetic pathways that establish cell diversity within the developing telencephalon have been identified, only a few factors have been shown to control the earliest steps of anteroposterior $(\mathrm{A} / \mathrm{P})$ and dorsoventral $(\mathrm{D} / \mathrm{V})$ patterning [1].
From embryonic stage E7.5 onwards, the telencephalic vesicles are progressively regionalized through complex interactions of secreted ligands from inductive centers, and by the regionalized or graded expression of transcription factors [1-3]. FGF (Fibroblast Growth Factor) signaling acts downstream of SHH (Sonic Hedgehog) and is required to both specify and promote the proliferation and/or survival of ventral cell types in the telencephalon [4-7], while WNT (Wint) signaling apparently elaborates archicortical morphogenesis $[8,9]$. Interestingly, modulation of the normal expression gradient of $F g f 8$ in the early 
cortical primordium alters the molecular location and the size of cortical domains along the $\mathrm{A} / \mathrm{P}$ axis $[10,11]$. At the beginning of cortical neurogenesis, several transcription factors display graded expression in cortical progenitors along the main axes, which seems to confer cortical regional specificity [1-3]. The transcription factors Emx2 and Pax6 exhibit an opposing expression gradient along the $\mathrm{A} / \mathrm{P}$ axis of the forebrain. Accordingly, single mutants of either Emx2 or Pax 6 show a severe shrinkage of the corresponding cortical area, which normally expresses these genes at high levels [2]. Of note, Emx2 is the only factor that has been shown to additionally affect the innervation of thalamic axons into the cortex [1-3].

The zinc-finger transcription factor Sp8 is expressed in the developing nervous system, limbs and the tail bud. Analysis of $S p 8$ knockout mice revealed severe truncations of the limbs and tail, while at the midbrain-hindbrain boundary (MHB) a defect of A/P patterning occurred (12, $13,14)$. Interestingly, Fgf8 expression is affected in both cases, suggesting that Sp8 may be required for the maintenance of $F g f 8$ activity in these tissues. Recent evidence indicates that abolishment of Sp8 function (in the ventral telencephalon) provokes enhanced apoptosis in progenitors of the dorsal lateral ganglionic eminence (dLGE), causing the loss of specific olfactory bulb interneurons [15]. Additionally, Sp8 displays a graded expression pattern in cortical progenitors, with highest expression in the medial pallium.

To gain more insights into the role of Sp8 in the developing telencephalon, we created Foxg1-Cre-mediated conditional $S p 8$ mutants. We present evidence that, in the absence of Sp8, while Shh signaling is normal, the D/V patterning at the medial telencephalic wall is perturbed. Midline derivatives of the subpallium are malformed or completely missing. Additionally, due to the modulation of the graded expression territories of Emx2 and Pax6 in pallial progenitors, a caudalization of cortical areas occurs. Our study indicates that Sp8 function is required to prevent pallial progenitors from apoptosis, and to control the molecular specification of subsets of cortical layer neurons. This is consistent with an essential role for Sp8 in the patterning of the developing forebrain along the $\mathrm{A} /$ $\mathrm{P}$ and $\mathrm{D} / \mathrm{V}$ axes. Furthermore, our findings support the idea of a direct interaction between $\mathrm{Sp} 8$ and $\mathrm{Emx} 2$ proteins.

\section{Results}

\section{Sp8 mutant brains exhibit multiple malformations}

At E8.0-E8.5, Sp8 is strongly expressed in the anterior neural ridge (Figure 1a). At stage E9.5, Sp8 mRNA is apparent in the entire forebrain anlage in a rostral-ventral/high, caudal-dorsal/low gradient. Additionally, $S p 8$ transcripts were detected in the olfactory placode (Figure 1b; data not shown). After E10.5, cortical Sp8 mRNA levels decrease, although keeping the typical mediolateral expression gradient in cortical progenitors (Additional data file 1). During later developmental stages, $S p 8$ transcription is further down-regulated within the cortical ventricular zone (VZ), but remains strongly evident throughout adulthood in the septum (SE), dLGE and olfactory system [15] (data not shown). To gain more insights into the role of $S p 8$ during forebrain development, we generated mice with a floxed $S p 8$ locus. $S p 8$ floxed mice were crossed with mice expressing the Cre-recombinase under the control of the Foxg1 promoter [16] (Additional data file 1) and the floxed allele was bred to homozygozity (termed cKO).

Homozygous Sp8 mutants died at birth. Mutant E10.5 forebrains lacked detectable levels of $S p 8$ mRNA (Figure 1d). At midgestation cKO embryos showed strong craniofacial abnormalities (data not shown). Nissl-stained histological sections revealed that $\mathrm{CKO}$ embryos displayed a dysgenesis of the olfactory bulbs (data not shown) and SE, including an almost complete absence of the midline (15\% penetrance, $\mathrm{n}=25$ ) that resulted in a mild rostral holoprosencephaly (Figure 1e, $e^{\prime}, e^{\prime \prime}$; Additional data file 2 ). In addition, the thickness of the cortical plate of the cKO cortex was reduced (Figure 1g, g'; $63.5 \% \pm 5.1 \%$ of control, $\mathrm{n}=10)$. The basal ganglia consisted of a single eminence (Additional data file 2) with a barely discernable constriction between the LGE and MGE. Corticofugal fiber tracts did not cross the midline and instead formed probst bundles (Figure 1e, $e^{\prime}, e^{\prime \prime}$ ). Caudally, neuronal fibers formed bundles between the internal and external capsules (arrows in Figure 1f, $f^{\prime}, f^{\prime}$ ).

\section{Sp8 modulates the D/V patterning of the medial telencephalon}

The loss of $S p 8$ activity in the forebrain provokes structural perturbations of the SE and MGE and prompted us to look for molecular markers associated with forebrain patterning. Whole mount in situ hybridization (WMISH) at E9.5 (after the initiation of Cre activity [16]) revealed that the mean expression levels of Pax 6 and Emx2 are, conversely, down- and up-regulated in cKO (Figure 2c, c', d, $\left.d^{\prime}\right)$ compared to wild-type embryos. Importantly, the activity of both $\mathrm{Fgf8}$ and Shh seemed unchanged in the absence of Sp8 (Figure 2a, a', e, e'). Remarkably, Nkx2.1 mRNA [17] was reduced in cKO. Rostrally, the septum anlage was free of $N k x 2.1$ transcripts (red arrow in Figure $\left.2 \mathrm{~b}, \mathrm{~b}^{\prime}\right)$, and the caudal portion of the MGE anlage was devoid of Nkx2.1 activity (white arrow in Figure $2 \mathrm{~b}, \mathrm{~b}^{\prime}$ ). At E10.5, Fgf8 mRNA was evident in the telencephalic midline, including the septum anlage (Figure $2 \mathrm{f}, \mathrm{f}^{\prime}$ ). Interestingly, at E12.5, we found that the Fgf8 expression domain in the SE of the mutants was specifically lost (Figure $2 \mathrm{~g}$, $\left.\mathrm{g}^{\prime}\right)$, while the expression of Shh [4,7] appeared to be unaffected (data not shown). This suggests that $S p 8$ function 


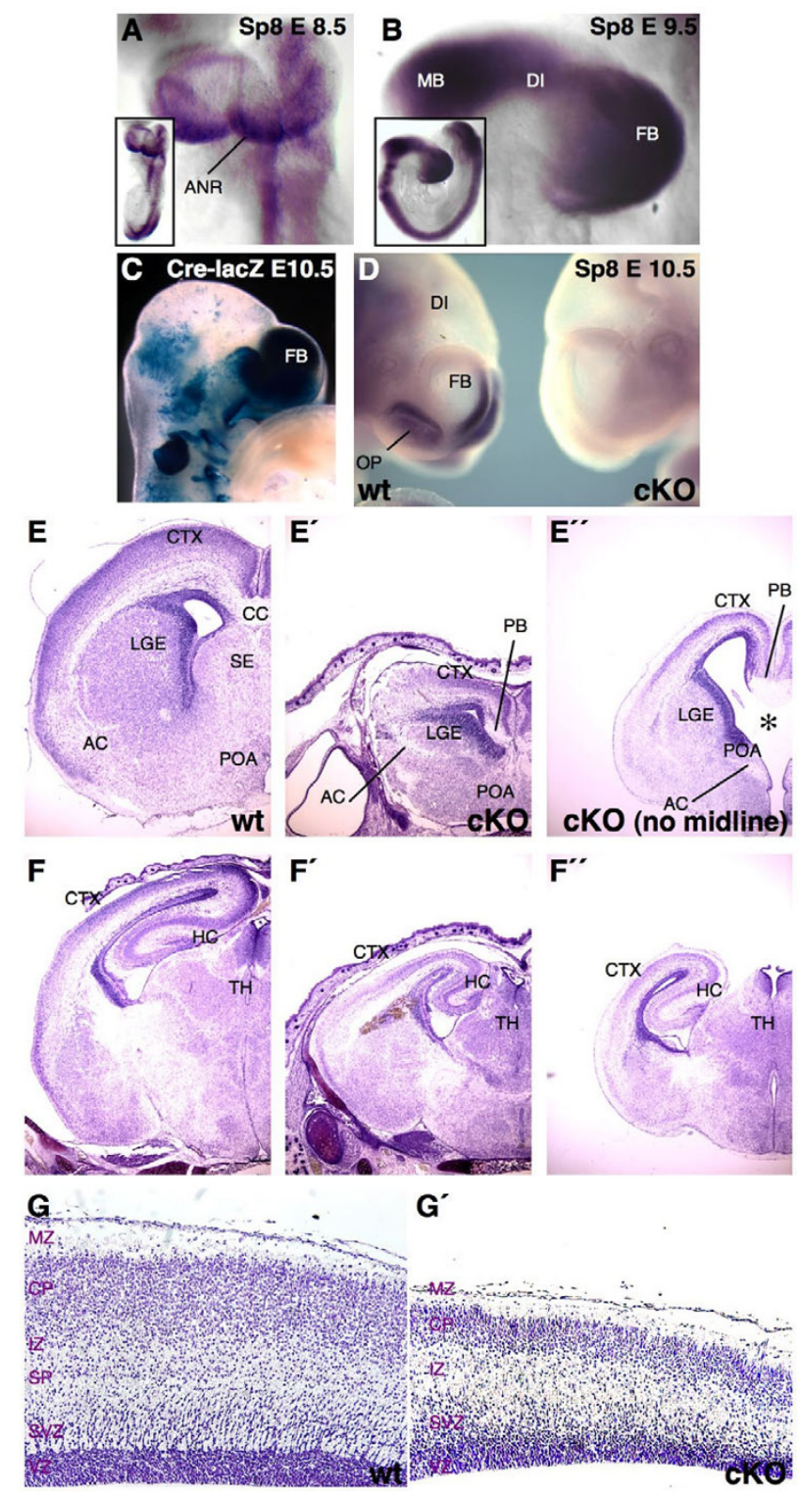

\section{Figure I}

Phenotype of conditional Sp8 mutants. (a, b) WMISH of Sp8 in E8.5 and E9.5 embryos. Sp8 is strongly expressed in the anterior neural ridge and in the forebrain neuroepithelium at E8.5 (a). At E9.5, Sp8 expression covers the putative forebrain vesicle (b). (c) Foxg I-Cre activity, visualized by X-Gal staining, is evident throughout the telencephalon at EI0.5. (d) Cre recombination ablates Sp8 expression in the telencephalon and olfactory placode of cKO at EI0.5. (e, $\left.\mathbf{f}^{\prime}\right)$ Histological (nissl stained) coronal sections at EI8.5. (e', f') Mutant brains miss the septum and reveal a reduced size of the telencephalon. (e', $\left.\mathbf{e}^{\prime \prime}\right)$ Callosal fibers do not cross the midline and form probst bundles unilaterally. (g, g') On (nissl stained) sagittal sections, a strongly reduced cortical diameter is characteristic for $\mathrm{CKO}$ at EI8.5. With I5\% penetrance, cKO brains show an enhanced phenotype, highlighted by the complete absence of midline derivates. These mutants were termed 'cKO no midline' (e", $\left.\mathrm{f}^{\prime \prime}\right)$. cKO and 'cKO no midline' only differ at rostral levels of the forebrain. In 'cKO no midline' specimens, a delamination of the cortex from the basal telencephalon is apparent medially, as a visible hole (asterisk in e"). Caudally in the brain, the difference between low and high penetrance of the phenotypes is not significant $\left(f^{\prime}, f^{\prime \prime}\right)$. AC, anterior commissure; $A N R$, anterior neural ridge; CC, corpus callosum; CP, cortical plate; CTX, cortex; DI, diencephalon; FB, forebrain; HC, hippocampus; IZ, intermediate zone; LGE, lateral ganglionic eminence; $M B$, midbrain; $M Z$, marginal zone; OP, olfactory placode; PB, probst bundles; POA, preoptic area; SE, septum; SP, subplate; SVZ, subventricular zone; TH, thalamus; VZ, ventricular zone. 
might be required for the maintenance of the late expression of Fgf8 in the telencephalic midline.

Next, we examined the patterning of the expression interface at the border of the pallium/subpallium in the medial telencephalic wall, designated medial pallial-subpallial boundary (mPSB). At the MPSB, both the Emx2+ and Pax6+ expression domains were expanded ventrally (arrows in Figure 3c, c', d, d'). Similarly, the Pax6 target gene [18], Ngn2, displayed ectopic expression in the presumptive territory of the SE (Figure $3 e, e^{\prime}$ ). In accordance with the reported inhibition of the ventral marker Mash1 by Ngn2 [19], the Mash1+ territory at the MPSB was reduced in $\mathrm{CKO}$ (Figure $3 \mathbf{j}, \mathbf{j}^{\prime}$ ). A similar down-regulation of the expression of the ventral markers Gsh2 [20-22] and Dlx1 [23] (arrows in Figure 3h, h', g, g') was also evident in the dorsal SE. At E15.5, the Ngn2 expression domain was still massively enlarged in the medial telencephalic wall, and thus, the expression domain of Dlx1 remained severely shrunken (Figure 3l, l', m, m'). Intriguingly, despite the partially preserved expression domain of Nkx2.1 in the presumptive MGE territory at E9, examination of E12.5 and E15.5 mutant embryos revealed that Nkx2.1 expression was almost absent from the subpallium (Figure 3f, f, n, n'). The only exception was a small stripe in the putative caudal ganglionic eminence (data not shown). Furthermore, the Nkx6.2+ domain that normally marks the MGE/LGE junction [5] was shifted medially and reached the ventrally expanded Emx2+, Pax6+, and $\mathrm{Ngn} 2+$ midline territories in cKO (Figure $3 \mathrm{k}, \mathrm{k}^{\prime}$; see also Figure $\left.3 c, c^{\prime}, d, d^{\prime}, e, e^{\prime}\right)$. Given the loss of substantial parts of the MGE during embryonic development, where the neuronal progenitors mainly generate interneurons [17], cKO cortices contained a strongly reduced amount of Gad67+ interneurons at E18.5+ $(20.3 \pm 2.7 \%$ of wild type, $\mathrm{n}=3$; Figure $3 \mathrm{o}, \mathrm{o}^{\prime}$ ). Our analysis further indicated that the expression boundaries of Pax6 (Figure 3b, b'), Ngn2 (Figure 3e, e'), Dlx1 (Figure 3g, g'), Mash1 (Figure 3j, $\left.j^{\prime}\right)$, and Gsh2 (Figure 3h, h') at the lateral pallial-subpallial boundary (PSB) were not altered in Sp8-deficient brains. This demonstrates that the molecular identity of the lateral pallium and LGE $[17,20-22]$ is not affected by the absence of Sp8. In contrast, our data are consistent with a role for $S p 8$ in the D/V patterning in the medial telencephalic wall.

To study whether the $\$ p 8$ mutation might affect pattern formation through the Wnt signaling pathway [8], we examined the expression of Wnt3a, Wnt5a and Wnt7b in the cortical hem and the Wnt antagonist Sfrp2 in the antihem. No change in the expression of these markers was apparent (data not shown). We concluded that Sp8 might act downstream or independently of Wnt signaling $[5,7,10]$.

\section{Abnormal cortical arealization and thalamic innervation in Sp8 mutants}

In the embryonic brain, Sp8 and Emx2 show similar expression characteristics along the medial-lateral axis (high at caudomedial levels and low at rostrolateral levels; Figure 3; Additional data file 1). Interestingly, the pallial $E m \times 2$ gradient is clearly up-regulated in mutant embryos at E12 (arrow in Figures 3a, a' and 4a, a'). Conversely, Pax6 normally displays an expression gradient that is high in the rostrolateral and low in the caudomedial pallium, opposing that of Emx2. These two genes mutually control their activities in the cortical neuroepithelium [1]. In accordance with the enhanced expression level of Emx2, Pax6 mRNA is clearly reduced in cKO (arrow in Figure 3b, $\mathrm{b}^{\prime}$; Figure 4b, b'). Given the crucial roles played by Emx2 and Pax6 in the arealization of the neocortex [1$3,10,24,25]$, their altered expression in $S p 8$ mutants prompted us to analyze cortical arealization. The expression of the EphA7 receptor and the EphrinA5 ligand specifically demarcates the regions of the motor/visual and somatosensory cortex, respectively $[24,26]$. In the cKO, the EphrinA5 somatosensory domain extends rostrally (Figure 4c, c'). Accordingly, the motor cortex area, which normally expresses EphA7 at high levels, shrinks (Figure $4 \mathrm{~d}, \mathrm{~d}^{\prime}$ ). A similar alteration was observed for the characteristic expression of Coup-TF1, normally showing a prominent caudal/high to rostral/low expression gradient $[21,27]$. In $S p 8$ mutants the strong caudal expression domain of Coup-TF1 expanded much more rostrally, reaching the presumptive motor cortex (arrows in Figure $\left.4 e, e^{\prime}\right)$. A caudalization of the molecular properties along the $\mathrm{A} / \mathrm{P}$ axis of the cortex was also evident, when $I D-2$ expression was examined. High ID-2 levels in upper cortical layers (arrowhead in Figure 4f) of the motor cortex and in layer $\mathrm{V}$ in the caudal cortex normally highlight the border between the motor and somatosensory domains $[2,3]$ (red arrow in Figure 4f). In $S p 8$ mutants the caudal $I D-2$ expression territory extends ectopically into the rostral cortex. Additionally, in the presumptive motor cortex, $I D$ 2 expression in upper cortical layers was abolished (Figure $\left.4 f^{\prime}\right)$.

To study whether the observed molecular caudalization of the Sp8cKO cortex reflects alterations of the cortical area identity, we performed retrograde labeling of thalamocortical (TCA) projections by placing crystals of the lypophilic dies $\mathrm{DiI}$ (red) and $\mathrm{DiO}$ (green) in the presumptive visual cortex or somatosensory area, respectively (insets in Figure 4g, g'). In controls, the red dye was exclusively present in cells within the dorsal lateral geniculate nucleus (dLGE; dorsal from the dashed line in Figure 4g), while the DiO labels (in green) cells in the ventroposterior complex (VP; ventral from the dashed line in Figure 4g). In the Sp8KO brain, the dLGE was labeled by TCA projections coming from both visual and somatosenory cortex 


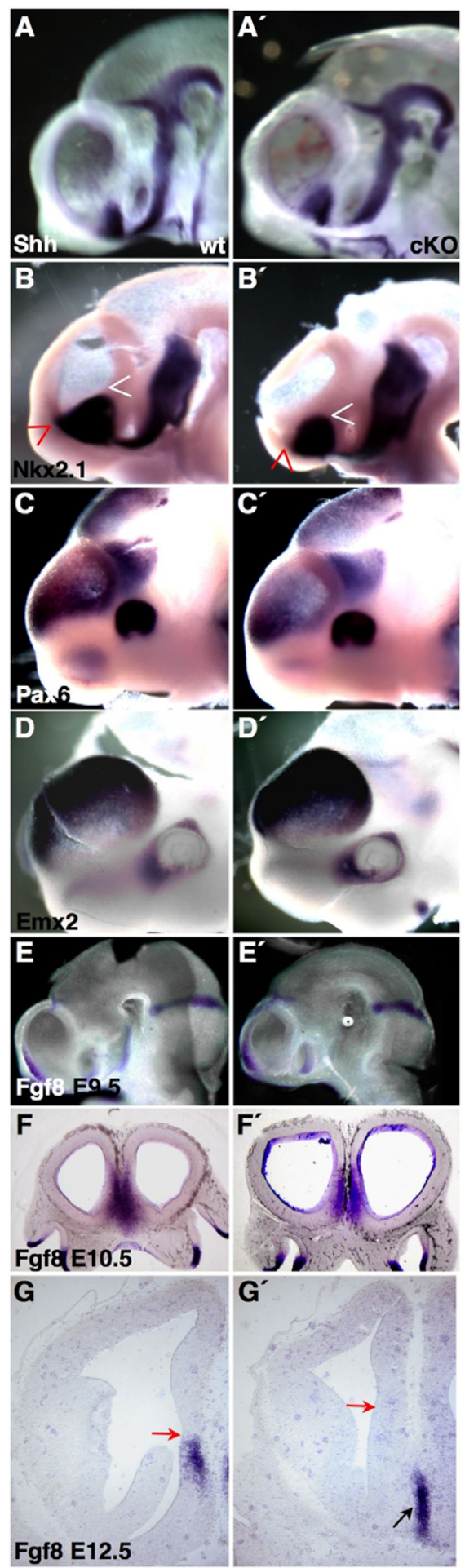

\section{Figure 2}

Early patterning of the cKO forebrain. (a-f') WMISH and $\left(g, g^{\prime}\right)$ ISH on sections. Shh (a, a') and Fgf8 expression (e, e') at E9.5 is unchanged in cKO. The septum and large parts of the MGE anlage (red and white arrowheads in (b, b')) are free of $N k x 2$.I activity. Pax6 activity is diminished in $\mathrm{CKO}\left(\mathrm{c}, \mathrm{c}^{\prime}\right)$. Emx2 is slightly up-regulated in mutants (d, d'). At EI0.5, Fgf8 is expressed in the telencephalic midline and septum anlage in both genotypes (f, $f$ ). At EI2.5, Fgf8 mRNA is specifically lost in the septum (red arrow in $\left.\left(g, g^{\prime}\right)\right)$. The Fgf8 positive domain in cKO at EI 2.5 matches the midline of the POA (black arrow in $\left.\left(g^{\prime}\right)\right)$. 


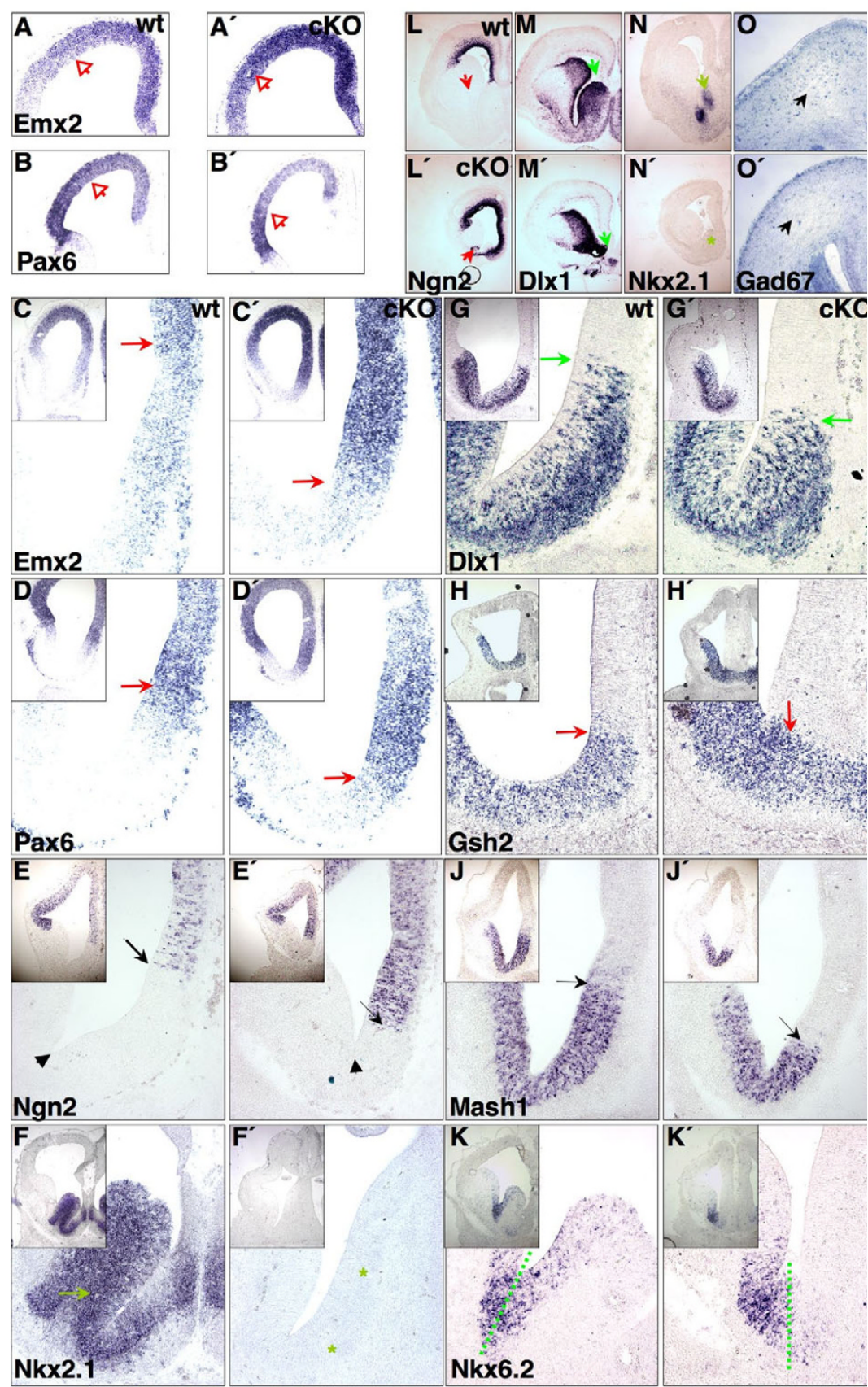

Figure 3

D/V patterning defects at the medial pallial-subpallial boundary (mPSB). ISH on EI 2.5 (coronal) forebrain sections. Images show the right brain hemisphere. (c-k') Blow-up images of the medial/ventral part of each boxed section. In cKO, the pallial markers (a, a', c, c') Emx2, (b, b', d, d') Pax6, and (e, e') Ngn2 expand into the ventral midline. Conversely, ventral markers (g, g')

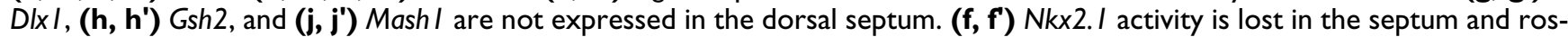
tral MGE of Sp8 mutants. (k, k') The Nkx6.2+ domain reflects a rudimentary MGE territory in cKO and contacts the Emx2+, Pax6+ and Ngn2+ midline. Note the (l, l') expansion of the Ngn2+ domain (arrows) and the ( $\left.\mathbf{m}, \mathbf{m}^{\prime}\right)$ reduction of the Dlxl+ domain (arrows) around the midline of the Sp8 deficient telencephalon at El5.5. (n, n') Nkx2.I (arrow) remains absent in the septum and rostral MGE of cKO at this stage. (o, o') Depletion of (Gad67+) interneurons in the Sp8 mutant cerebral cortex (arrow) at El8.5. For a better visualization of the shift in gene expression pattern, the arrowheads in (e, e') point at the constriction between the septum anlage and the LGE. ISH for Emx2/Pax6 (a, a', b, b', c, c', d, d') and Ngn2/Mash I riboprobes (e, e', j, j') were performed on adjacent sections. 


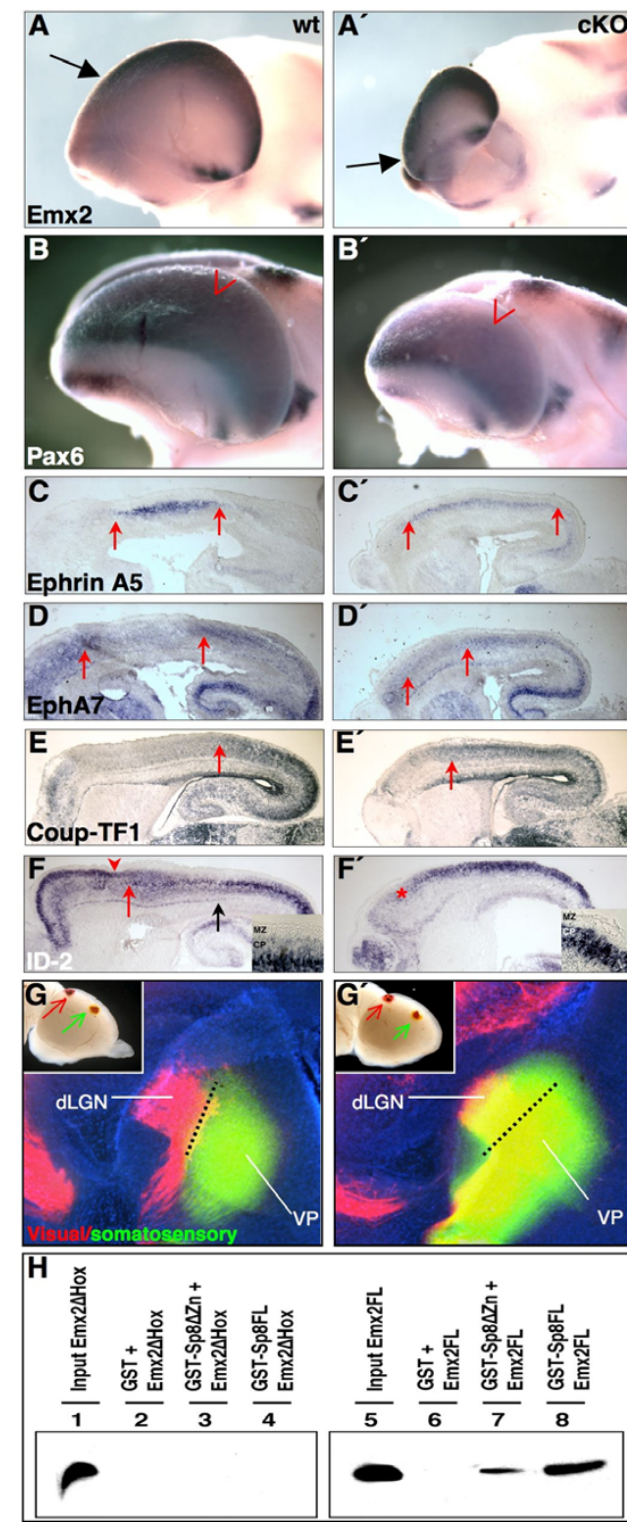

\section{Figure 4}

Caudalized gene expression and thalamic innervation in the brain of Sp8 mutants. (a, a', b, b') WMISH on dissected EI2.5 forebrains, using Emx2 and Pax6 riboprobes. The Emx2 gradient is up-regulated in cKO (arrows in (a, $\left.a^{\prime}\right)$ ). The expression level of Pax6 is diminished (arrowheads in (b, b')) in Sp8 mutants. Analysis of the area specific marker genes (c, c') EphrinA5, (d, $\left.\mathbf{d}^{\prime}\right)$ EphA7, (e, e') Coup-TFI and (f, f') ID-2 on EI8.5 sagittal sections using ISH (rostral is to the left). The visual cortex area in cKO cortices appears expanded towards the rostral brain, as demonstrated by EphA7, ID-2 and Coup-TFI expression (strong rostral domain of EphA7 in (d'), strong ID-2 domain in ( $\left.f^{\prime}\right)$, strong domain of Coup-TFI in (e')). The somatosensory cortex (area between the red arrows in (c, d') and between the black and red arrows in (f)) shifts rostrally in Sp8 conditional mutants (compare (c, d) with ( $\left.c^{\prime}, d^{\prime}\right)$, and ( $f$ ) with the area indicated by the asterisk in (f')). The motor cortex expression area appears condensed (compare rostral to left arrow in (c, c', d, d')) in Sp8 deficient specimens. (g, g') Coronal sections of El 8.5 brains labeled with Dil and $\mathrm{DiO}$ and counterstained with DAPI. In controls, Dil, placed in the visual cortex (inset in (g)), retrogradelly labels only cells in the dLGN (g). Placing DiO in the somatosensory cortex (inset in (g)) marks only cells in the VP (g). In the mutants the green dye, placed into somatosensory cortex (inset in $\left(\mathrm{g}^{\prime}\right)$ ) labels cells in the VP and the dLGN ( $\left.\mathrm{g}^{\prime}\right)$. (h) GST-pull

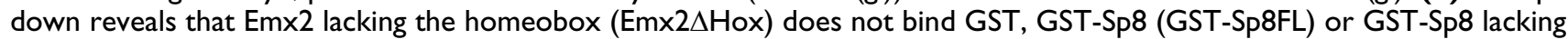

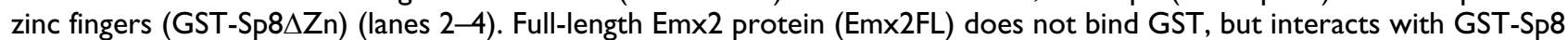
(GST-Sp8FL) and GST-SP8 lacking zinc fingers (GST-Sp8 $\Delta \mathrm{Zn}$ ) (lanes 6-8). Lanes I and 5 show $10 \%$ of the radiolabeled Emx2 isoforms, used as input for the binding assays in lanes 2-4 and 6-8. 
(Figure 4g'). These results suggest that the molecular caudalization of the Sp8KO cortex causes a partial change in the cortical area identity (somatosensory to visual fate).

To elucidate whether the regulation of Emx2 by Sp 8 might be direct or indirect, we performed biochemical in vitro experiments. Glutathione S-transferase (GST)-pull down assays revealed that truncated Emx2 protein, lacking the homeobox, does not interact with GST-Sp8 or GST-Sp8 without zinc fingers (Figure 4h, lanes 3 and 4). However, we found that GST-Sp8 as well as GST-Sp8 lacking zinc fingers are able to bind the full-length Emx2 protein in vitro (Figure $4 \mathrm{~h}$, lanes 7 and 8 ). Taken together, this indicates that the Sp8 expression gradient in cortical progenitors plays an important role in the correct positioning of distinct cortical domains along the A/P axis of the developing cortex by modulating the expression level of Emx2. Furthermore, our findings support the idea of a direct interaction between Sp8 and Emx2 proteins.

\section{Sp8 controls cell survival in the developing forebrain}

The hypoplasia provoked in the forebrain of $\mathrm{cKO}$ led us to speculate that this may be related to defects in cell proliferation and/or apoptosis [28,29]. Such alterations were additionally observed in Foxg1 knockout mice [30]. However, Foxg1 activity was not affected in Sp8 mutants (data not shown). We therefore determined the bromodeoxyuridine (BrdU) labeling index (BrdU pulse), M-Phase index (pH3 staining), and cell cycle exit [30,31] (BrdU/iododeoxyuridine (IdU) double labeling) parameters in the forebrain of $\mathrm{cKO}$ at E12.5. None of these parameters were significantly altered in mutant forebrains (Additional data file 3). Furthermore, neither ectopic mitosis nor premature differentiation seems to occur in cKO (Additional data file 3). However, using a TUNEL assay at E12.5, we detected a dramatic increase of apoptosis in forebrain sections (Figure 5a, $a^{\prime}$ ). TUNEL+ cells were found randomly distributed in the dorsal and basal telencephalon (Figure 5a, a', b, b' ; data not shown). The apoptotic cells formed clusters consisting of three to six individual nuclei (arrow in Figure 5c). Counting of TUNEL+ cells on E10.5, E15.5 and E18.5 sections revealed that the Sp8-deficient forebrains contained six times more apoptotic cells at E10.5 and three times more from E12.5 to E18.5 compared to controls (Figure 5e). TUNEL+ nuclei were found in putative proliferative regions (white arrows in Figure 5d) and in the cortical plate proper (CP; blue arrow in Figure $5 \mathrm{~d}$ ). Sp8 deficiency possibly affects the survival of some postmitotic neurons (Figure 5d; 78.4\% TUNEL+/Tuj- at E15.5, $\mathrm{n}=2$ ), but mainly early (E10.5-E12.5) neuronal progenitors. Thus, the forebrain hypoplasia in cKO appears as a consequence of the apoptosis-induced loss of progenitors.

We next wanted to know whether the observed loss of progenitors might affect the generation of specifically early- or late-born cortical neurons [32]. By injecting BrdU at E12.5 or E15.5 and sampling at E18.5, we created specimens that had BrdU exclusively incorporated in early(E12.5) or late-born (E15.5) neurons. Analysis of the samples injected at E12.5 identified cells populating deep and intermediate positions of the CP (Figure 5f). In accordance with the detected apoptosis, the number of BrdU+ nuclei in mutant brains was reduced (Figure 5f ; $64.7 \pm$ $7.8 \%$ of wild type, $\mathrm{n}=3$ ), pointing to a diminished progenitor pool. Cells labeled with BrdU at E15.5 populated mainly deep compartments (VZ, subventricular zone (SVZ), intermediate zone (IZ)) of the cortex of both genotypes (Figure $5 \mathrm{~g}, \mathrm{~g}^{\prime}$ ). However, the amount of BrdU+ cells within the putative SVZ, which were recently shown to generate exclusively upper cortical layers [33-35], appeared reduced in the mutants (yellow arrow in Figure $\left.5 g^{\prime}\right)$. Conversely, more BrdU-labeled cells were detected in superficial positions in the CP (white arrow in Figure $5 g^{\prime}$ ), most probably reflecting the reduction in the distance from the ventricular to the marginal zone in the mutant cortex.

\section{The loss of Sp8 results in defective preplate splitting}

The apoptotic cell death detected in the forebrain of $S p 8$ mutant embryos may also affect neurogenesis and early cortical layer development. The cortical preplate (PPL) consists of early-born (E10-E11.5) neurons of pallial origin. Later-born neurons will progressively split this domain into the marginal zone (MZ), CP and subplate (SP) $[36,37]$. We used the Tbr1 riboprobe to label early PPL and SP populations [38,39] at mid-gestation. While in controls Tbr1+ SP cells are well separated from Tbr1+ CP cells (Figure 6a), this does not occur in cKO embryos (Figure 6a').

Furthermore, we used a cell labeling approach consisting of injecting BrdU at E11 to label SP cells [36,40] and then harvesting tissue after a visible separation of SP and CP at E15 (Figure 6a). In addition, the co-detection of BrdU and Tbr1 enabled us to follow the laminar position of the double positive cells, which in controls were found in the SP (arrow in Figure 6b). In contrast, in cKO these cells were located in virtually the most superficial part of the cortical plate (compare Figure $6 \mathrm{~b}, \mathrm{~b}^{\prime}$ ). We conclude that proper PPL splitting does not occur in Sp8cKO.

In accordance with defective SP formation [37-40], Gap43 antibody staining revealed that the subcortical connectivity and the axonal wiring appeared abnormal in mutants. In contrast to controls, Gap43+ fibers in Sp8 mutants formed aberrant bundles within the internal capsule, with some axons projecting ectopically towards the $\mathrm{MZ}$ (arrows and arrowheads in Figure 6d, d') and basal telencephalon (Additional data file $2\left(\mathrm{~d}, \mathrm{~d}^{\prime \prime}\right)$ ). 

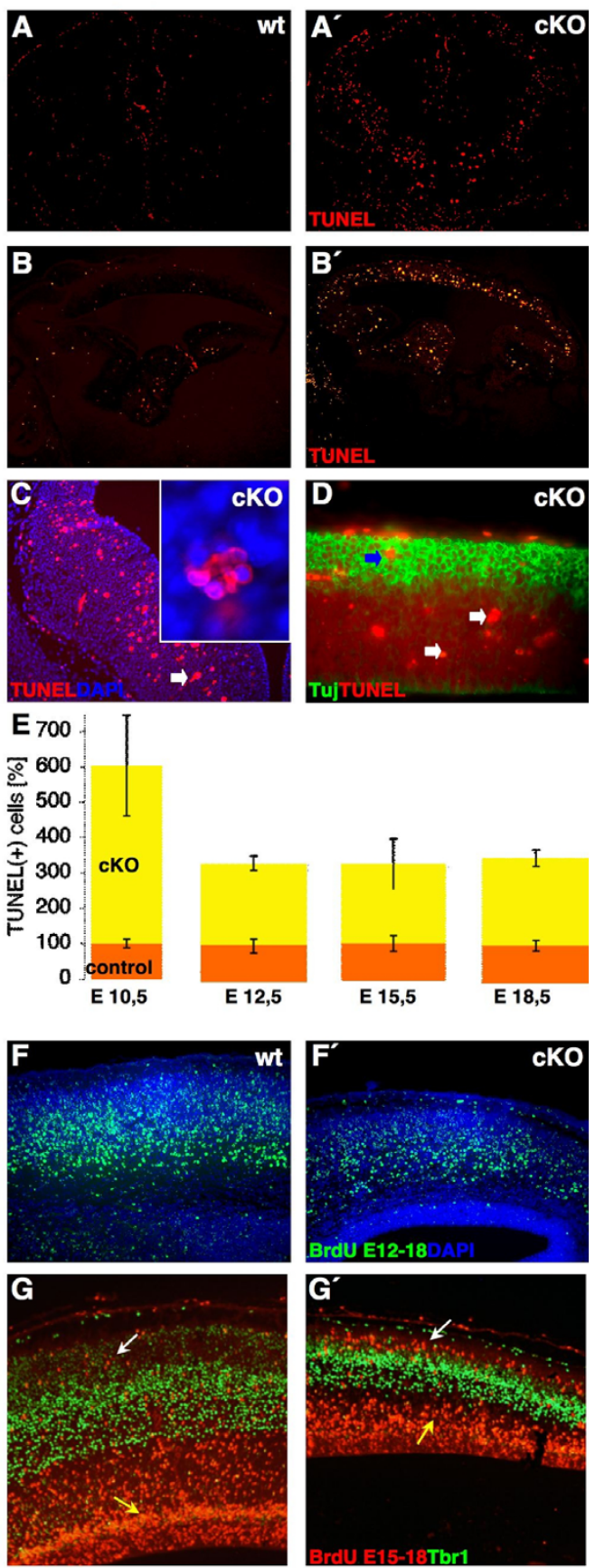

\section{Figure 5}

Apoptotic cell death in Sp8 deficient brains. TUNEL staining on (a, a', c) EI2.5 (coronal) and (b, b', d) EI5.5 forebrain sections (sagittal; rostral is to the left). The arrow in (c) demarcates a typical cluster of apoptotic cells, found in cKO, and found from EI2.5 to EI8.5. Clusters typically contained five to seven apoptotic cells (blow-up in (c)). (d) Tuj/TUNEL double staining in cKO reveals TUNEL+ cells within the putative CP (blue arrow) and presumptive proliferative zones and the IZ (white arrows). (e) Quantification of TUNEL+ nuclei on EI0.5, EI2.5, EI5.5 and EI8.5 forebrain sections ( $\mathrm{n}=3-4$ for each stage) shows an increased cell death without Sp8 function. Fate mapping of (f, $\left.\mathbf{f}^{\prime}\right)$ early-born and $\left(\mathbf{g}, \mathbf{g}^{\prime}\right)$ late-born pallial neurons (using BrdU injection at EI2.5 or EI5.5) on EI8.5 sagittal sections. Putative early-born neurons migrate through the CP (f, $f^{\prime}$ ). Their number is diminished in mutant cortices ( $f$ ') compared to controls (f). In cKO, BrdU+ neurons populate ectopic positions in the upper $\mathrm{CP}$, when compared to the relative position of Tbrl immunoreactive cells (white arrow in $\left(\mathrm{g}^{\prime}\right)$ ), possibly reflecting the thinned cortex. BrdU labeling at EI5.5 appears reduced in the SVZ of mutants (yellow arrow in $\left(\mathrm{g}^{\prime}\right)$ ). 


\section{E15.5}
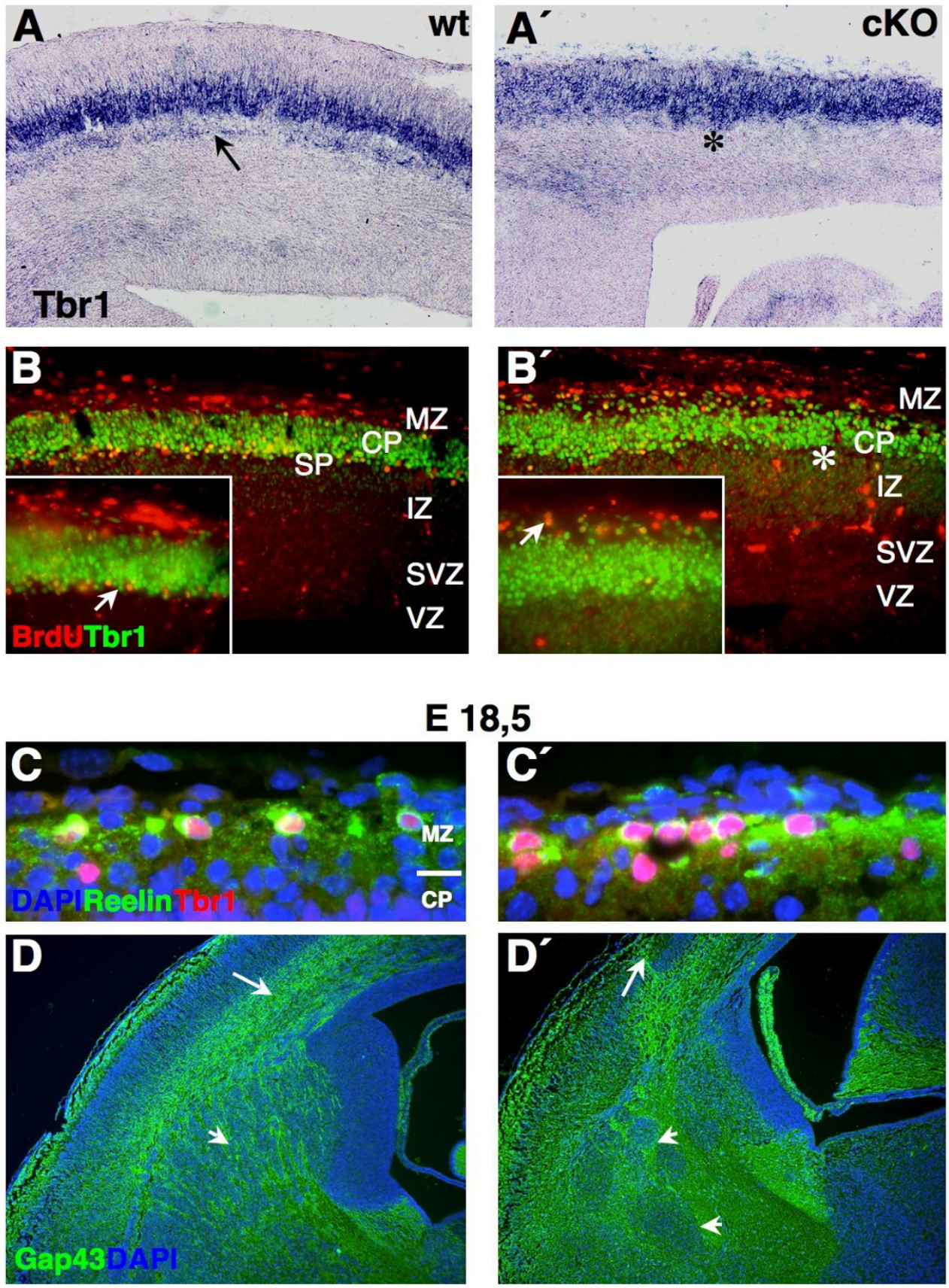

Figure 6

Defective preplate splitting and subplate development. (a, a') ISH for Tbrl transcript on EI 5.5 coronal sections (medial is to the right). (b, b') Immunohistochemical co-detection of Tbrl and BrdU on EI5.5 sagittal sections (rostral is to the left). Mutants lack well separated/positioned Tbrl+, putative subplate cells at EI5.5 (arrow and asterisk in (a, a')). At this stage, $\mathrm{BrdU}+$ (injected EII) cells co-labeled with TbrI form a superplate-like structure by populating the upper CP/MZ in cKO (arrow in (b)). In controls, those cells settle in the subplate area (arrow in (b)). Arrows indicate the dislocation of BrdU+/ Tbrl+ cells in mutants (b'). Co-detection of Reelin- and Tbrl protein in the MZ on coronal sections at EI8.5 (c, c') (medial is to the right) cKO showed more Reelin+/Tbr I+ (putative Cajal-Retzius cells) in the MZ (c'). The PPL does not split properly in cKO; additionally Gap43+ axons (assayed on EI8.5 coronal sections) form bundles around the internal capsule (arrowheads in $\left(d, d^{\prime}\right)$ and some project ectopically into the $M Z$ (arrow in $\left.\left(d, d^{\prime}\right)\right)$. 


\section{Perturbed specification of distinct cortical layer neurons in Sp8 mutants}

Because the detected PPL defect may provoke additional abnormalities, we investigated whether the generation of infra-/supragranular layers and the differentiation of specific neuronal layers were altered in cKO. We therefore labeled late-born/upper cortical neurons with the Cux2 riboprobe [34,35], combined with immunolabeling for Tbr1, tracing early-born/deep layer neurons [41]. We could not observe co-localization (Figure 7a, a') of both markers, demonstrating that the basic laminar organization of the cortex and the switch from early to late neuronal fate is not altered in mutants. To examine whether $S p 8$ might be required for the specification of distinct cortical neuron subtypes, we assayed layer-specific marker genes at E18.5. Recent findings $[36,41]$ indicate that Tbr1 activity is able to promote the specification of the SP and layer VI. In accordance with defective preplate splitting and the apoptotic cell death of progenitors in $\mathrm{CKO}$, the analysis of Tbr1 expression by immunohistochemistry or in situ hybridization revealed ectopic Tbr1+ cells in the uppermost region of the CP (arrows in Figure 7l'), and a less thick band corresponding to layer VI of the deep CP (Figure $\left.7 \mathrm{k}, \mathrm{k}^{\prime}\right)$. In addition, ER81 was used to trace a subpopulation of layer $\mathrm{V}$ neurons [42], but we could not detect ER81 mRNA in CP neurons at E18.5 (Figure $7 \mathbf{j}, \mathbf{j}^{\prime}$ ). However, the expression of another marker of layer $\mathrm{V}$ neurons (Robo1 [42]) appeared to be only diminished in cKO (Figure $\left.7 \mathrm{~h}, \mathrm{~h}^{\prime}\right)$, suggesting that only a subset of lower cortical layers might not be correctly specified.

The orphan nuclear receptor $R z R-\beta$ was utilized to follow layer IV genesis [42]. At E18.5, $R z R-\beta$ transcripts were completely missing in the CP of mutants (compare Figure $7 \mathrm{f}, \mathrm{f}^{\prime}$ ). Moreover, the expression of Cux proteins in SVZ progenitors was recently shown to promote the fate specification of late-born neurons [34,35]. Accordingly, we found that in the mutant, although Cux2 expression was reduced (Figure $7 \mathrm{~d}, \mathrm{~d}^{\prime}$ ), Cux 1 mRNA could not be detected at E18.5 (Figure $7 c, c^{\prime}$ ). Along the same line of evidence, the expression of an additional upper layer neuron marker, $L h x 2$, is also highly down-regulated in the cortical plate of $S p 8$ mutants (Figure $7 \mathrm{e}, \mathrm{e}^{\prime}$ ). This suggests that a reduction in the generation of late-born/upper cortical layer neurons occurs. We assayed Tbr2 immmunoreactivity. Tbr2 is a specific marker for basal/SVZ progenitors [43], which predominantly generate the upper cortical layers $[34,35]$. In $S p 8$ mutants, the population of Tbr2+ (basal) progenitors was significantly reduced at E18.5 $\left(49.4 \pm 4.3 \%\right.$ of controls, $n=3$; Figure $\left.7 g, g^{\prime}\right)$. This is consistent with a diminished pool of late progenitors, resulting in a diminished generation of upper cortical layer neurons in conditional $S p 8$ mutants.
The MZ mostly consists of Reelin+ Cajal-Retzius cells $[1,9,37]$. Using in situ hybridization (ISH) for Reelin mRNA (and a Reelin antibody for quantification) we found more Reelin+ neurons in $\mathrm{cKO}$ than in control littermates $\left(142.2 \pm 6.4 \%\right.$ of controls; Figures $6 c$, $c^{\prime}$ and $\left.7 b, b^{\prime}\right)$. In summary, these findings support the idea that the lack of $5 p 8$ function during early neurogenesis is responsible for a severe depletion of the early and the late cortical progenitor pool, resulting in a misspecification of distinct cortical neuron subtypes, such as Cux1+, Lhx2+, RzR- $\beta+$, and ER81+ lineages.

\section{Discussion}

We used conditional inactivation to study the role of $S p 8$, the ortholog of the Drosophila transcription factor buttonhead [13], during murine forebrain development. We report that the absence of Sp8 provokes a morphological dysplasia of the rostromedial forebrain, perturbs A/P patterning and enhances apoptosis of neuronal progenitors. A marker analysis further revealed that although the layering of the mutant cerebral cortex seems normal, Sp8 function is required for the specification of neuronal subpopulations.

\section{Sp8 has an essential role in the formation of the telencephalic midline}

One morphologically apparent defect was the dysgenesis of the septum. On the molecular level, this might result from the ventral expansion of Emx2, Pax6 and Ngn2 expression territories. As a consequence, the expression of several ventral markers, such as Fgf8, Mash1, Dlx1, and most importantly, $N k x 2.1$ is regionally down-regulated or completely abolished. Interestingly, Shh and Wnt expression seems to be preserved in the mutant, suggesting that the observed perturbation is independent of these signaling pathways. Our findings suggest that $S p 8$ might have a critical role in the maintenance of gene activity at the $\mathrm{mPSB}$, since early marker expression is not affected. Interestingly, both $S p 8$ and $F g f 8$ are expressed in the septum anlage at early developmental stages. Recent findings demonstrate that FGF signaling is acting downstream of Shh to propagate ventral telencephalic cell types and to promote their survival [6]. Our study reveals that, while preserved in the midline and septum anlage until E10.5, the expression of Fgf8 (in the septum) and Nkx2.1 (in the septum and rostral MGE) is completely abolished at E12.5. Moreover, a recent report provides evidence that Fgf8 may regulate Nkx2.1 expression, interfering with the axial patterning of the telencephalon [7], therefore suggesting that the midline defect in $\mathrm{CKO}$ could be mediated through Fgf8.

It was recently found that $S p 8$ is down-regulated in the medial telencephalon of $F g f 8$ hypomorphic and conditional mutants [7]. Strikingly, it was demonstrated by 


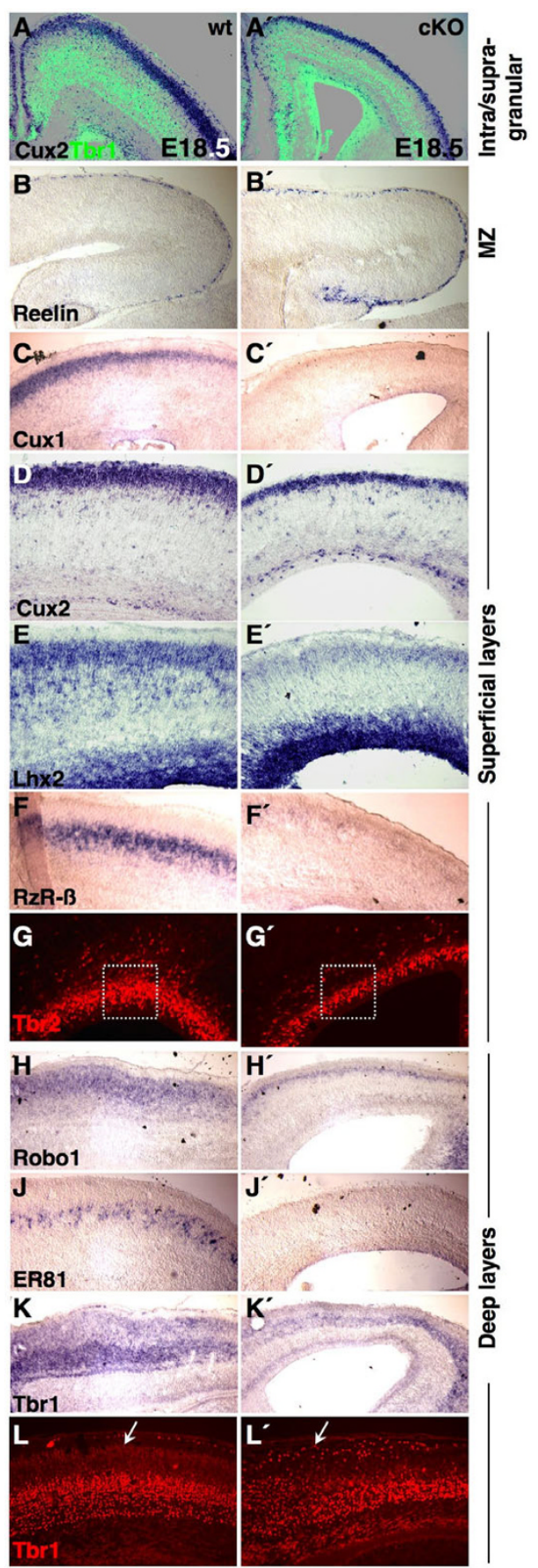

\section{Figure 7}

Specification of individual cortical layer neurons. Coronal (EI8.5) sections were double labeled with the Cux2 riboprobe and the Tbrl antibody. (a, a') Cux2+ and Tbrl+ cell populations are separated from each other, and the generation of intra-/supragranular layers seems preserved in Sp8 mutants. ISH of layer specific marker genes on (c, $\left.\mathbf{c}^{\prime}, \mathbf{f}, \mathbf{f}^{\prime}, \mathbf{j}, \mathbf{j}^{\prime}\right)$ EI8.5 coronal (medial is to the right) and (b, b', d, d', e, e', h, h', k, k') sagittal (rostral is to the left) forebrain sections. (g, g', I, I') Detection of Tbr I/ 2 protein on El8.5 coronal sections (medial is to the right). A reduced expression of Cux2 (d, d'), Lhx2 (e, e'), Robol (h, h') and $\operatorname{Tbrl}\left(\mathrm{k}, \mathrm{k}^{\prime}\right)$ is visible in mutant cortices. In Sp8cKO, the subpopulations of CuxI+ (c, c'), RzR- $\beta+\left(\mathrm{f}, \mathrm{f}^{\prime}\right)$, and ER8I+ (j, j') cortical neurons are not molecularly specified. Tbr2 immunoreactive progenitors are diminished in the proliferative compartment of the Sp8 mutant cortex (box in $\left(g, g^{\prime}\right)$ ). Immunohistochemistry reveals that some $\mathrm{Tbrl}+$ cells ectopically populated the upper CP and $M Z$ in Sp8 mutants (arrow in (l')). 
three independent studies that Sp8 might positively regulate Fgf8 expression in the mouse AER [12,13], and in the zebrafish pectoral fin [44]. Conversely, the loss of $S p 8$ in the MHB provokes an expansion of the Fgf8 expression domain [14]. Therefore, an attractive interpretation of the defect at the medial wall might be that a context-dependent bidirectional interaction between $F g f 8$ and $S p 8$ is responsible for the correct patterning of the ventro-medial telencephalon. Recently, FGF signaling was shown to be crucial for the genesis of the SE [45]. In the absence of late Fgf8 activity in Sp8cKO, the septal territory abnormally expresses dorsal markers, and therefore, might acquire pallial properties (Figure 8), supporting the idea that Fgf8 and Sp8 may also be required for sustaining ventral cellular identity of septal precursors.

Although Sp8 is expressed in the dLGE, the patterning at the PSB is not disturbed. Two possibilities might be envisioned: first, the D/V patterning at the PSB is established before E9, 5; and second, functional redundancy may exist between $S p 8$ and the closely related transcription factor $S p 9$ [44] in the ventral telencephalon (Additional data file 1).

\section{Sp8 affects cortical arealization along the A/P axis}

We recently have shown that $S p 8$ knockout mice display a patterning defect at the MHB [14]. In the present study we demonstrate that, in addition to its role in the formation of a normal mPSB, Sp8 is necessary for the molecular arealization of the cerebral cortex along the $\mathrm{A} / \mathrm{P}$ axis. The arealization of the early cortical primordium is dependent on the regionalized expression of ligands belonging to the FGF, WNT/BMP and epidermal growth factor signaling pathways, produced by the anterior neural ridge (ANR), cortical hem, roof plate and antihem, respectively $[1,3]$. Such ligands are assumed to control the graded expression of transcription factors, encoding positional pattern, and specific for distinct cortical fields. So far, only a few regionally enriched transcription factors have been shown to be critical for this process. For instance, in mice where either Pax6 or Emx2 is not functional, the corresponding rostral and caudal cortical regions, where these genes display highest expression, appear malformed and cortical areas are displaced in opposite directions $[2,46]$.

Our findings suggest that the inactivation of $S p 8$ in the forebrain causes a prominent caudalization of the molecular properties of the cortical neuroepithelium, as highlighted by the ectopic rostral expansion of the expression domains of the regionally enriched marker genes CoupTF1, EphrinA5 and EphA7. Furthermore, Sp8cKO cortices show an enhanced $E m \times 2$ and a reciprocally down-regulated Pax6 expression gradient. This supports the notion that the genetic interplay between Pax6 and Emx2 is controlling the establishment of their normal expression gra- dients [47]. However, the loss of Emx2 or Pax6 function does not affect the expression of $S p 8$, suggesting that $S p 8$ acts upstream of these genes (Additional data file 1).

FGF signaling from the ANR plays a crucial role in the patterning along the cortical A/P axis [1]. Evidence has been presented that $E m \times 2$ might indirectly control cortical arealization, through the regulation of Fgf8 [10]. Recent data, however, challenged such a view by demonstrating that $E m \times 2$ may operate directly, and independent of, Fgf8 to specify cortical areas [25]. In addition, it was shown that thalamocortical connectivity is affected only in the absence of proper Emx2 function [48], and conversely does not change in Fgf8 hypomorphic cortices in vivo [11]. In good agreement with these findings we observe defects in thalamocortical projections in Sp8cKO cortices. Notably, the early FGF signaling from the ANR does not seem to be affected in the Sp8cKO forebrain until at least E10.5. Taken together, our findings strongly suggest leading roles for $E m \times 2$ and Sp8 in cortical arealization.

In agreement with findings in Drosophila, we show a direct interaction between Sp8 and Emx2 proteins in vitro, indicating a conservation of this regulatory pathway [49].

\section{Sp8 plays a critical role in cortical neurogenesis}

Enhanced apoptosis was detected in the limbs [13] and basal telencephalon in Sp8 loss-of-function mice [15]. We show here that the forebrain hypoplasia in Sp8cKO mice is primarily due to cell death, affecting both early and late progenitor pools of dorsal and ventral telencephalon.

We further found that when the function of Sp8 is abolished, the preplate splitting is defective, and the $\mathrm{MZ}$ contains more Reelin+ cells [50], possibly due to the enhanced Emx2 expression in the mutant cortex. The basic lamination of the cortex is not compromised in cKO. However, the specification of particular neuronal subtypes (such as ER81-, RzR- $\beta$-, and Cux1-positive) is affected. Similarly, conditional ablation of $S p 8$ in the basal telencephalon results in misspecification of a subset of interneurons [15].

\section{Conclusion}

Our findings provide evidence that the transcription factor $\mathrm{Sp} 8$ is required for both the early patterning of the forebrain and the specification and survival of ventral cell types of the telencephalon. Our findings support the idea that a direct interaction between Sp8 and Emx2 controls $\mathrm{D} / \mathrm{V}$ patterning of the medial telencephalon, functional arealization along the $\mathrm{A} / \mathrm{P}$ axis, and the specification of subpopulations of cortical layers. 

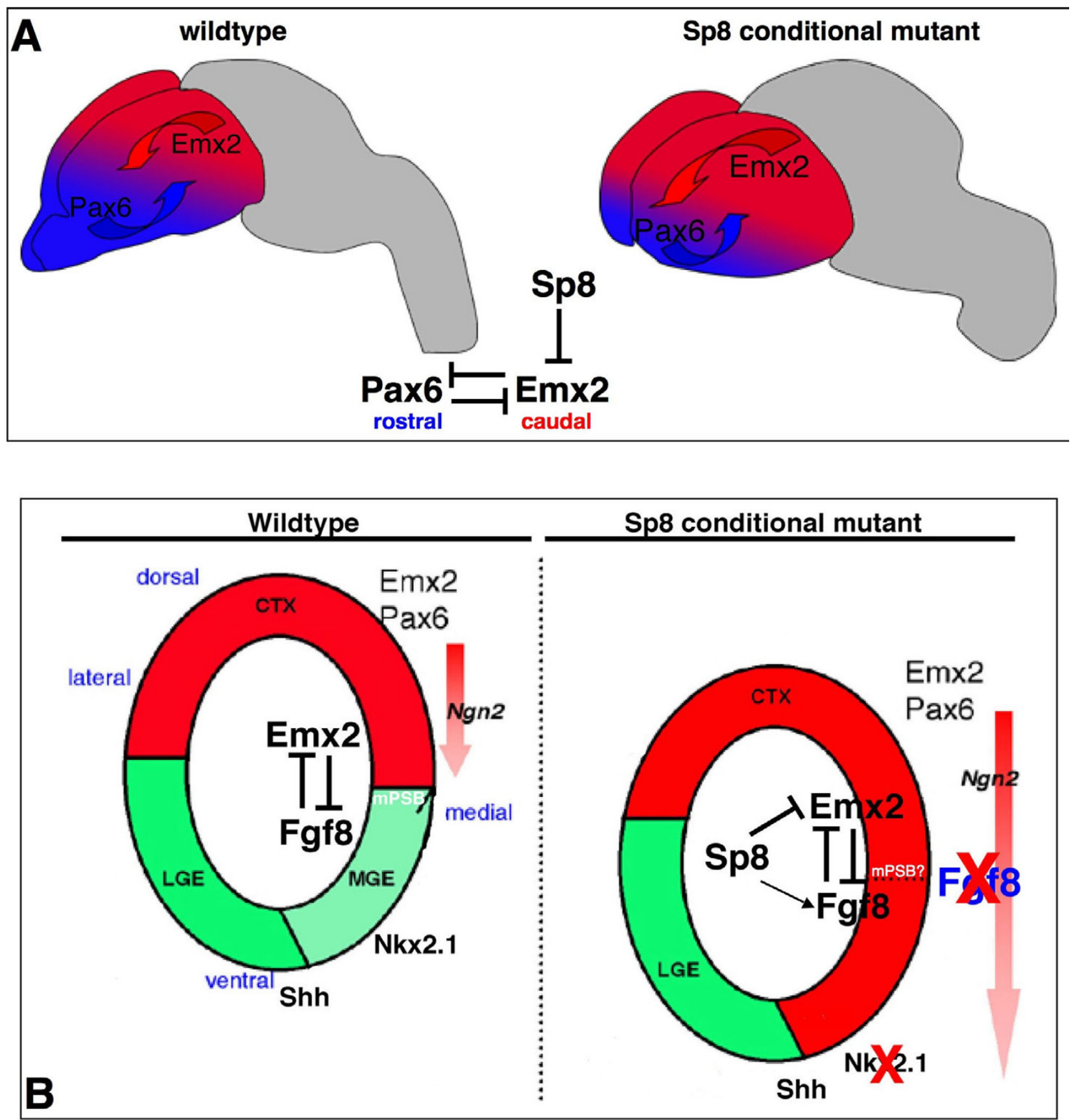

Figure 8

Role of Sp8 in the forebrain. (a) A scheme illustrating the genetic interplay between Sp8 and Emx2. Emx2 and Pax6 mutually affect their graded expression characteristics along the A/P axis (red and blue arrows). Sp8 acts as a repressor of Emx2 to pattern the forebrain along the A/P axis. In $\mathrm{CKO}$, the mutant Emx2 expression domain (red) is expanded rostrally. Accordingly, Pax6 expression territory (blue) is diminished. (b) Scheme recapitulating the gene expression of marker genes at the medial and lateral PSB. In conditional Sp8 mutant, a dorsalization of gene activity around the midline occurs, as highlighted by the ventral expansion of the domain marked in red. Dorsal: red domain, Pax6, Emx2, Ngn2; ventral: green and light-green domain, Gsh2, Dlx I, Mash I. Reciprocally, the expression area of ventral markers is lost in the dorsal septum (light green domain). Accordingly, Fgf8 and Nkx2.I expression domains are not maintained in the mutant cortical midline. We favor a model in which Sp8 regulates the AP regionalization of cortex by directly suppressing Emx2, while the role of Sp8 in the maintenance of $\mathrm{Nkx2}$. I activity in SE and MGE could consist of controlling Fgf8. 


\section{Materials and methods Generation of Sp8 conditional mutant mice}

Animal treatment and housing was in agreement with the regulations of LAVES (Landesamt für Verbraucherschutz und Lebensmittelsicherheit) in Oldenburg. The different alleles of $S p 8$ are represented in Additional data file 1. Exons are indicated by black boxes, LoxP sites by black triangles and FRT (Flip recombination target) sites by white triangles. The LoxP-FRT-PGKneo-FRT cassette was inserted 5 ' to exon 1 and the second LoxP site 3 ' to exon 3. Southern blot analysis, using probes $\mathrm{A}, \mathrm{B}$ and $\mathrm{C}$ (Figure 1b) identified recombinant clones. Hybridization with probe $\mathrm{D}$ (Additional data file 1) confirmed the deletion of the wild-type $S p 8$ allele. Homozygous $S p 8$ floxed mice were maintained on a C57/BL6 background. Conditional Sp8 knockout animals were generated by mating $S p 8$ floxed mice with Foxg1-Cre mice [16] (cKO). Cre activity was monitored using R26R reporter mice [51]. Cre+ cells were traced in triple transgenic mice, obtained by crossing $S p 8$ floxed heterozygous mice (positive for the Cre recombinase) with R26R mice (cKO-R26R).

Genotyping was done by PCR using the following primers: Sp8 (1: CCA-ATG-GGA-GGA-AAA-CAC-ACC-CCCTCT-TAC-TCC-TC, 2: CCA-GCT-TCC-TGG-ACT-CTT-TCAGTA-TAG-TTT-TGA-AG， 3: GCG-TGC-AAT-CCA-TCTTGT-TCA-ATG-GCC-GAT-C); Cre (creF: ATG-CTT-CTGTCC-GTT-TGC-CG, creR: CCT-GTT-TTG-CAC-GTT-CACCG); $\beta$-galactosidase (lacZF: TTG-GCG-TAA-GTG-AAGCGA-C, lacZR: AGC-GGC-TGA-TGT-TGA-ACT-G).

\section{Embryo recovery and tissue sampling}

Pregnancy of mated mice was determined by the appearance of the vaginal plug and defined as day E0.5. Staging of embryos was done according to the plug date. Mice were killed by cervical dislocation. Embryos or tissues were dissected, washed in cold phosphate-buffered saline (PBS) and fixed in 4\% PFA/PBS (paraformaldehyde) for several hours overnight. After rinsing in PBS, tissues were processed for standard paraffin- or cryo-embedding. Tissues were cryo-protected by overnight incubation in $30 \%$ sucrose/PBS at $4{ }^{\circ} \mathrm{C}$. Embedding was done in tissue tec (Jung, Nussloch, Germany) and freezing on dry ice. For whole mount ISH, dissected embryos were processed through a methanol series and kept at $-20^{\circ} \mathrm{C}$.

\section{Immunohistochemistry, X-Gal staining and in situ hybridization}

Immunohistochemistry was performed on $18 \mu \mathrm{m}$ cryosections, or paraffin embedded sections of $5 \mu \mathrm{m}$ to $10 \mu \mathrm{m}$ thickness. Antigens were generally unmasked by boiling in citrate buffer (Vector, Burlingame, CA, USA), as described elsewhere. Primary antibodies were $\mu$-Pax6 (Babco, Richmond, CA, USA), $\mu$-Gap43, $\mu$-Tuj (Covance, Berkeley, CA, USA), $\mu$-BrdU, $\mu$-phospho-HistoneH3
(Abcam, Cambridge, UK), $\mu$-BrdU/IdU (Caltag, Burlingame, CA, USA), $\mu$-Tbr1+2 (gift from R Hevner), and $\mu$ Reelin (gift from A Goffinet). Paraffin sections were dewaxed, rehydrated and rinsed in PBS. Cryosections were washed in PBS and postfixed in 4\% PFA/PBS. After unmasking, sections were blocked in a solution containing PBT (PBS $+0.1 \%$ TritonX) and 10\% FCS (fetal calf serum) for 30 minutes. Primary antibodies were incubated overnight at $4^{\circ} \mathrm{C}$ in blocking solution. Secondary antibodies were diluted 1:500 in blocking solution and incubated for 1-2 hours at room temperature. Secondary antibodies were Alexa594- or Alexa488-conjugated and raised against mouse-, rabbit- or rat antigens (Molecular Probes, Karlsruhe, Germany). Before mounting, sections were rinsed three times in PBT and sealed with Vectashield mounting medium, containing DAPI as nuclear counterstain (Vector).

$\mathrm{X}$-Gal staining was performed on whole mount tissue or $18 \mu \mathrm{m}$ cryosections. $\beta$-Galactosidase activity was developed in staining solution (PBS, $1 \mathrm{mg} / \mathrm{ml} \mathrm{X-Gal,} 2 \mathrm{mM}$ $\mathrm{MgCl}_{2}, 0.01 \%$ SDS, $0.02 \% \mathrm{NP} 40,5 \mathrm{mM} \mathrm{K}_{3} \mathrm{Fe}(\mathrm{CN})_{6}, 5 \mathrm{mM}$ $\mathrm{K}_{4} \mathrm{Fe}(\mathrm{CN})_{6}$ ) for several hours overnight at $37^{\circ} \mathrm{C}$. Specimens were then washed in PBS and postfixed in PFA. Sections were counterstained in a solution containing $0.1 \%$ neutral red.

ISH on $12 \mu \mathrm{m}$ to $18 \mu \mathrm{m}$ cryosections and whole mount ISH were performed using digoxygenin labeled riboprobes, as described previously $[13,14]$. Histological analysis was done on nissl stained or neutral red counterstained sections, following standard procedures.

\section{Axon tracing}

E18.5 brains were fixed in PFA overnight and dissected from the skull. After hemi-sectioning the brains with a blade, crystals of DiI and DiO (Molecular Probes) were placed into multiple, but comparable, locations of the cortex $[11,48]$ across genotypes $(n=6$ hemi-sections per genotype and experiment). The diffusion of the tracers was allowed to proceed for 4 weeks in PFA at $37^{\circ} \mathrm{C}$. After embedding the brains in 5\% LMP-Agarose, $100 \mu \mathrm{m}$ coronal sections were cut on a vibratome and counterstained with DAPI containing mounting medium (Vector).

\section{BrdU labeling and TUNEL assay}

BrdU and IdU (Sigma, Seelze, Germany) uptake experiments were done by intraperitoneal injection $(50 \mu \mathrm{g} / \mathrm{g}$ body weight) of nucleotides into pregnant mice. For pulse labeling, injected mice were sacrificed 30 minutes after injection. Tissues of BrdU-injected embryos were processed for paraffin embedding. Subsequently, 5-10 $\mu \mathrm{m}$ sections were used for immunohistochemistry. 
The S-Phase labeling index was estimated by dividing DAPI+ from BrdU+ cells on complete forebrain sections. For fate mapping purposes, BrdU was injected at varying time points from E10.5 to E15.5. Tissues were dissected on E15.5 to E18.5, respectively. The cell cycle length was estimated by sequential BrdU/IdU injection, according to $[30,31]$. The (cell cycle) leaving fraction was counted by dividing IdU+/BrdU+ cells from IdU+ only cells on forebrain sections.

TUNEL assay was performed on $5 \mu \mathrm{m}$ paraffin sections of E10, E12, E15 and E18 brains using a ApopTag Red In Situ Apoptosis Detection kit (Chemicon, Hampshire, UK) and following the manufacturer's advice. The amount of TUNEL+ cells in control specimens of every stage was defined as $100 \%$. Apoptotic cell clusters were identified in cKO from E12.5 to E18.5 and counted as one apoptotic cell.

\section{In vitro pull-down assay}

The cDNA encoding Sp8 (Sp8FL, AA 1-486) and Sp8 lacking zinc fingers (Sp8 $\Delta \mathrm{Zn}$, AA 1-355) were amplified by PCR (MGI-Clone 2443471) using the following PCR primers, adding 5' BamHI and 3' EcoRI restriction sites: Sp8FL forward and Sp8 $\Delta \mathrm{Zn}$ forward, G CGC GGA TCC ATG CTT GCT GCT ACC TGT AAT AAG ATC; Sp8FL reverse, G CGC GAA TTC CTC CAG GCC GTT GCG GTG; Sp8AZn reverse, G CGC GAA TTC CAG CCC TTT GCG ACG CAG GC. PCR products were then subcloned in frame into the BamHI and EcoRI restriction sites of the pGEX-4T-3 expression vector (Promega, Madison, WI, USA). GST and GST-Sp8 fusion proteins were expressed in Escherichia coli and purified following standard protocols. Equal amounts of GST-Sp8 proteins or GST were incubated with gluthathione-sepharose beads (Amersham, Piscataway, NJ, USA) and washed in PBS.

The cDNA encoding Emx2 (Emx2FL, AA 1-253) and Emx2 lacking the homeobox (Emx2 $\Delta$ Hox, AA 1-144) were amplified by PCR using the following PCR primers, adding 5' EcoRI and 3' NotI restriction sites: Emx2FL forward and Emx $2 \Delta$ Hox forward, G CGC GAA TTC ATG TTT CAG CCG GCG CC; Emx2FL reverse, GCG CGC GGC CGC ATC GTC TGA GGT CAC ATC; Emx2 $\Delta$ Hox reverse, GCG CGC GGC CGC GCC AGG GGT AGA AGG TGG ACG. Template DNA containing the Emx2 open reading frame was kindly provided by A Mallamaci. Amplified PCR products were then subcloned into the EcoRI and NotI restriction sites of the pCMV-TNT vector (Promega). [35S]-methionine labeling of Emx2 proteins was performed using the TNT Quick Coupled Transcription/ Translation system (Promega).

The GST and GST-Sp8 bound beads were then incubated with [ $\left.{ }^{35} S\right]$-methionine-labeled Emx2 protein isoforms in
$0.4 \mathrm{ml}$ binding buffer ( $0.1 \mathrm{M} \mathrm{NaCl}, 0.01 \% \mathrm{NP}-40)$. After incubation for 2 hours at $4{ }^{\circ} \mathrm{C}$, beads were washed five times in $400 \mu \mathrm{l}$ binding buffer and then boiled in $40 \mu \mathrm{l}$ of $10 \times$ SDS-PAGE loading buffer $(10 \%$ SDS, $10 \mathrm{mM} \beta$-mercaptoethanol, 20\% glycerol, $0.2 \mathrm{M}$ Tris- $\mathrm{HCl}, \mathrm{pH}$ 6.8, $0.05 \%$ bromophenolblue). Solubilized proteins were separated by $15 \%$ SDS-PAGE and the radiolabeled proteins visualized by autoradiography.

\section{Statistics and data processing}

Statistics were calculated with Microsoft Excel. Quantifications always represent the mean values of tested specimens. Analysis included error bars and the mean deviation. The total sample number is indicated in the corresponding figure legends or text sections. The different parameters were counted on captured images. Images were processed with Adobe Photoshop 7.0.

\section{Competing interests}

The author(s) declare that they have no competing interests.

\section{Authors' contributions}

AZ performed all the experiments and wrote the first draft of the manuscript. GG generated the Sp8 conditional knockout mice. AS and AM designed the experiments and wrote the final version of the manuscript. All authors approved the manuscript.

\section{Additional material}

\section{Additional data file 1}

Sp8 mRNA is expressed in Emx2KO and Pax6KO cortices. ISH using (a$\boldsymbol{c}, \boldsymbol{e})$ Sp8 and (d) Sp9 riboprobes on E12.5 coronal sections. Sp8 expression in the medial and dorsal pallium of Emx $2 \mathrm{KO}$ and Pax6KO specimens appears indistinguishable from controls $(a-c)$. Sp8 and Sp9 are expressed mostly in non-overlapping domains of the telencephalon $(d, e) . \mathrm{Sp} 9$ is detected at the pallial-subpallial border $(d)$. ( $f$ ) Scheme illustrating the generation of the floxed Sp8 allele. (g) Southern blot analysis revealed successfully recombined $\mathrm{Sp} 8$ floxed alleles and the deletion of the wild-type (wt) Sp8 allele. Restriction enzymes: $H$, HindIII; $K, \mathrm{KpnI} P$, PacI; R1, EcoRI; R5, EcoRV; S, SpeI; X, XbaI).

Click here for file

[http://www.biomedcentral.com/content/supplementary/1749-

8104-2-8-S1.jpeg] 


\begin{abstract}
Additional data file 2
Histological analysis of conditional Sp8 mutant forebrains. Nissl stained coronal sections at different developmental stages, as indicated. (a-f) Wild type $(W t),\left(a^{\prime}-f^{\prime}\right) c K O,\left(a^{\prime \prime}-f^{\prime \prime}\right) c K O$ no midline (most severe phenotype observed). At E12.5, conditional Sp8 mutant tissue sections revealed a significant size reduction of the telencephalon and the morphological absence of the septum at rostral levels $\left(a^{\prime}, a^{\prime \prime}\right)$. Caudally, the basal ganglia appear as a single eminence $\left(b^{\prime}, b^{\prime \prime}\right)$ when compared to controls (b). At E15.5, cKO forebrains lacked the septum $\left(c, c^{\prime}\right)$. Due to an almost complete disgenesis of the midline, the lateral ventricles appear as a single aqueduct space (compare (c) with the area indicated by the asterisk in $\left.\left(c^{\prime \prime}\right)\right)$. At more caudal levels, there is no obvious difference between Sp8cKO and Sp8cKO no midline. However, when compared to wild-type embryos, the internal capsule of conditional mutants showed aberrant fiber bundles extending towards the basal telencephalon (arrows in $(d, d$, $\left.d^{\prime \prime}\right)$ ). At E18.5, further reduction of the forebrain size and a variable dysgenesis of the midline were observed $\left(e, e^{\prime}, e^{\prime \prime}\right)$. Sp8-deficient embryos typically lack a discernable corpus callosum (CC); instead, unilaterally probst bundles (PB) were apparent $\left(e, e^{\prime}, e^{\prime \prime}\right)$.

Click here for file

[http://www.biomedcentral.com/content/supplementary/1749-

8104-2-8-S2.jpeg]

\section{Additional data file 3}

No evidence for cell cycle alterations in Sp8 mutants. Immunohistochemistry for $\left(\boldsymbol{a}, \boldsymbol{a}^{\prime}, \boldsymbol{b}, \boldsymbol{b}^{\prime}\right)$ Tuj and $\left(\boldsymbol{c}, \boldsymbol{c}^{\prime}\right)$ Tuj/Pax6 antibodies on coronal sections. Tuj staining revealed no difference in the thickness of the PP/CP at E10.5 $\left(a, a^{\prime}\right), E 12.5\left(b, b^{\prime}\right)$, and E15.5 $\left(c, c^{\prime}\right)$. Therefore, premature differentiation is not evident in cKO. Estimation of cell cycle parameters, using $\left(\boldsymbol{e}, e^{\prime}, f\right) \operatorname{BrdU},\left(\boldsymbol{e}, e^{\prime}, g\right)$ phosphor-histone H3, and $\left(\boldsymbol{d}, \boldsymbol{d}^{\prime}, \boldsymbol{h}\right)$ BrdU/IdU staining on E12.5 sections. None of the tested cell cycle parameters were significantly abnormal in Sp8 conditional mutants.

Click here for file

[http://www.biomedcentral.com/content/supplementary/17498104-2-8-S3.jpeg]
\end{abstract}

\section{Acknowledgements}

We would like to thank A Driehorst, H Fett, and the BTL animal facility crew for the excellent animal caretaking and S. Blanke for helping with the Pull-down assay experiments. We are indebted to $\mathrm{R}$ Hevner for kindly providing Tbrl/2 antibodies and to A Goffinet for providing Reelin antibody and fruitful discussion and J Ericson for the Nkx6.2 probe. We further would like to thank SK McConnell for providing the Foxgl-Cre mice and $A$ Mallamaci for providing the Emx2 cDNA. We additionally want to thank J Butler and $\mathrm{H}$ Fukumitsu for critically reading the manuscript. Finally, we would like to thank P. Gruss for constant support and encouragement. This work was supported by the Max Planck Society, the Dr Helmut Storz and Alte Leipziger Stiftung, the German Ministry for Education and Research BMBF (0IGN05I0), and the DFG Center for Molecular Physiology of the Brain (CMPB).

\section{References}

I. Mallamaci A, Stoykova A: Gene networks controlling early cerebral cortex arealization. Eur J Neurosci 2006, 23:847-856.

2. O'Leary DD, Nakagawa Y: Patterning centers, regulatory genes and extrinsic mechanisms controlling arealization of the neocortex. Curr Opin Neurobiol 2002, I 2: | 4-25

3. Sur M, Rubenstein JL: Patterning and plasticity of the cerebral cortex. Science 2005, 310:805-810.

4. Chiang C, Litingtung Y, Lee E, Young KE, Corden JL, Westphal H, Beachy PA: Cyclopia and defective axial patterning in mice lacking Sonic hedgehog gene function. Nature 1996, 383:407-4I3.

5. Xu Q, Wonders CP, Anderson SA: Sonic hedgehog maintains the identity of cortical interneuron progenitors in the ventral telencephalon. Development 2005, 132:4987-4998.

6. Gutin G, Fernandes M, Palazzolo L, Paek H, Yu K, Ornitz DM, McConnell SK, Hebert JM: FGF signalling generates ventral telencephalic cells independently of SHH. Development 2006, I 33:2937-2946.

7. Storm EE, Garel S, Borello U, Hebert JM, Martinez S, McConnell SK, Martin GR, Rubenstein JL: Dose-dependent functions of Fgf8 in regulating telencephalic patterning centers. Development 2006, 133:|83|-1844.

8. Theil T, Aydin S, Koch S, Grotewold L, Ruther U: Wnt and Bmp signalling cooperatively regulate graded $\mathrm{Em} \times 2$ expression in the dorsal telencephalon. Development 2002, I 29:3045-3054.

9. Muzio L, Soria JM, Pannese M, Piccolo S, Mallamaci A: A mutually stimulating loop involving em $\times 2$ and canonical wnt signalling specifically promotes expansion of occipital cortex and hippocampus. Cereb Cortex 2005, 15:2021-2028.

10. Fukuchi-Shimogori T, Grove EA: Emx2 patterns the neocortex by regulating FGF positional signaling. Nat Neurosci 2003, 6:825-831.

II. Garel S, Huffman KJ, Rubenstein JL: Molecular regionalization of the neocortex is disrupted in Fgf8 hypomorphic mutants. Development 2003, I30:1903-1914.

12. Bell SM, Schreiner CM, Waclaw RR, Campbell K, Potter SS, Scott WJ: Sp8 is crucial for limb outgrowth and neuropore closure. Proc Natl Acad Sci USA 2003, 100:12195-12200.

13. Treichel $D$, Schock $F$, Jackle $H$, Gruss $P$, Mansouri $A$ : mBtd is required to maintain signaling during murine limb development. Genes Dev 2003, I7:2630-2635.

14. Griesel G, Treichel D, Collombat P, Krull J, Zembrzycki A, van den Akker WM, Gruss P, Simeone A, Mansouri A: Sp8 controls the anteroposterior patterning at the midbrain-hindbrain border. Development 2006, 133:1779-1787.

15. Waclaw RR, Allen ZJ 2nd, Bell SM, Erdelyi F, Szabo G, Potter SS, Campbell K: The zinc finger transcription factor $S p 8$ regulates the generation and diversity of olfactory bulb interneurons. Neuron 2006, 49:503-516.

16. Hebert JM, McConnell SK: Targeting of cre to the Foxg I (BF-I) locus mediates loxP recombination in the telencephalon and other developing head structures. Dev Biol 2000, 222:296-306.

17. Sussel L, Marin O, Kimura S, Rubenstein JL: Loss of Nkx2.I homeobox gene function results in a ventral to dorsal molecular respecification within the basal telencephalon: evidence for a transformation of the pallidum into the striatum. Development 1999, 126:3359-3370.

18. Scardigli R, Baumer N, Gruss P, Guillemot F, Le Roux I: Direct and concentration-dependent regulation of the proneural gene Neurogenin2 by Pax6. Development 2003, 130:3269-328I.

19. Parras CM, Schuurmans C, Scardigli R, Kim J, Anderson DJ, Guillemot F: Divergent functions of the proneural genes MashI and Ngn2 in the specification of neuronal subtype identity. Genes Dev 2002, 16:324-338.

20. Toresson H, Potter SS, Campbell K. Genetic control of dorsalventral identity in the telencephalon: opposing roles for Pax6 and Gsh2. Development 2000, I 27:4361-4371.

2I. Corbin JG, Rutlin M, Gaiano N, Fishell G: Combinatorial function of the homeodomain proteins Nkx2.I and Gsh2 in ventral telencephalic patterning. Development 2003, 130:4895-4906.

22. Yun K, Garel S, Fischman S, Rubenstein JL: Patterning of the lateral ganglionic eminence by the Gsh I and Gsh2 homeobox genes regulates striatal and olfactory bulb histogenesis and the growth of axons through the basal ganglia. J Comp Neurol 2003, 46I: I5I- 165

23. Panganiban G, Rubenstein IL: Developmental functions of the Distal-less/DIx homeobox genes. Development 2002, I 29:437| I-4386.

24. Rubenstein JL, Anderson S, Shi L, Miyashita-Lin E, Bulfone A, Hevner $\mathrm{R}$ : Genetic control of cortical regionalization and connectivity. Cereb Cortex 1999, 9:524-532.

25. Hamasaki T, Leingartner A, Ringstedt T, O'Leary DD: EMX2 regulates sizes and positioning of the primary sensory and motor areas in neocortex by direct specification of cortical progenitors. Neuron 2004, 43:359-372. 
26. Nakagawa $Y$, Johnson JE, O'Leary DD: Graded and areal expression patterns of regulatory genes and cadherins in embryonic neocortex independent of thalamocortical input. J Neurosci 1999, 19:10877-10885.

27. Zhou C, Tsai SY, Tsai MJ: COUP-TFI: an intrinsic factor for early regionalization of the neocortex. Genes Dev 200I, I 5:2054-2059.

28. Depaepe V, Suarez-Gonzalez N, Dufour A, Passante L, Gorski JA, Jones KR, Ledent $C$, Vanderhaeghen P: Ephrin signalling controls brain size by regulating apoptosis of neural progenitors. Nature 2005, 435: I 244-I250.

29. Putz U, Harwell C, Nedivi E: Soluble CPGI5 expressed during early development rescues cortical progenitors from apoptosis. Nat Neurosci 2005, 8:322-331.

30. Martynoga B, Morrison H, Price DJ, Mason JO: Foxg I is required for specification of ventral telencephalon and region-specific regulation of dorsal telencephalic precursor proliferation and apoptosis. Dev Biol 2005, 283: I |3-127.

31. Burns KA, Kuan CY: Low doses of bromo- and iododeoxyuridine produce near-saturation labeling of adult proliferative populations in the dentate gyrus. Eur $J$ Neurosci 2005, 2 I :803-807.

32. Noctor SC, Martinez-Cerdeno V, Ivic L, Kriegstein AR: Cortical neurons arise in symmetric and asymmetric division zones and migrate through specific phases. Nat Neurosci 2004, 7:136-144

33. Tarabykin V, Stoykova A, Usman N, Gruss P: Cortical upper layer neurons derive from the subventricular zone as indicated by Svet I gene expression. Development 200I, I 28:1983-1993.

34. Nieto M, Monuki ES, Tang H, Imitola J, Haubst N, Khoury SJ, Cunningham J, Gotz M, Walsh CA: Expression of Cux-I and Cux-2 in the subventricular zone and upper layers II-IV of the cerebral cortex. J Comp Neurol 2004, 479: I68-I80.

35. Zimmer C, Tiveron MC, Bodmer R, Cremer H: Dynamics of Cux 2 expression suggests that an early pool of SVZ precursors is fated to become upper cortical layer neurons. Cereb Cortex 2004, | 4: |408-|420.

36. Kolk SM, Whitman MC, Yun ME, Shete P, Donoghue MJ: A unique subpopulation of Tbrl-expressing deep layer neurons in the developing cerebral cortex. Mol Cell Neurosci 2005, 30:538-55 I.

37. Molnar Z, Metin C, Stoykova A, Tarabykin V, Price DJ, Francis F, Meyer G, Dehay C, Kennedy H: Comparative aspects of cerebral cortical development. Eur J Neurosci 2006, 23:92I-934.

38. Xie Y, Skinner E, Landry C, Handley V, Schonmann V, Jacobs E, Fisher $R$, Campagnoni $A$ : Influence of the embryonic preplate on the organization of the cerebral cortex: a targeted ablation model. J Neurosci 2002, 22:8981-8991.

39. Dupont E, Hanganu IL, Kilb W, Hirsch S, Luhmann HJ: Rapid developmental switch in the mechanisms driving early cortical columnar networks. Nature 2006, 439:79-83.

40. Rakic S, Davis C, Molnar Z, Nikolic M, Parnavelas JG: Role of p35/ Cdk5 in preplate splitting in the developing cerebral cortex. Cereb Cortex 2006, I 6(Suppl I):i35-45.

4I. Hevner RF, Shi L, Justice N, Hsueh Y, Sheng M, Smiga S, Bulfone A Goffinet AM, Campagnoni AT, Rubenstein JL: Tbr I regulates differentiation of the preplate and layer 6. Neuron 200I, 29:353-366.

42. Schuurmans C, Armant O, Nieto M, Stenman JM, Britz O, Klenin N, Brown C, Langevin LM, Seibt J, Tang H, et al.: Sequential phases of cortical specification involve Neurogenin-dependent and independent pathways. EMBO J 2004, 23:2892-2902.

43. Englund C, Fink A, Lau C, Pham D, Daza RA, Bulfone A, Kowalczyk T, Hevner RF: Pax6, Tbr2, and Tbrl are expressed sequentially by radial glia, intermediate progenitor cells, and postmitotic neurons in developing neocortex. J Neurosci 2005, 25:247-25I.

44. Kawakami Y, Esteban CR, Matsui T, Rodriguez-Leon J, Kato S, Belmonte JC: Sp8 and Sp9, two closely related buttonhead-like transcription factors, regulate Fgf8 expression and limb outgrowth in vertebrate embryos. Development 2004, I 3 |:4763-4774.

45. Tole S, Gutin G, Bhatnagar L, Remedios R, Hebert JM: Development of midline cell types and commissural axon tracts requires Fgfrl in the cerebrum. Dev Biol 2006, 289:|4|-|5I.

46. Kimura J, Suda Y, Kurokawa D, Hossain ZM, Nakamura M, Takahashi M, Hara A, Aizawa S: Emx2 and Pax6 function in cooperation with Otx2 and OtxI to develop caudal forebrain primordium that includes future archipallium. I Neurosci 2005, 25:5097-5108.

47. Muzio L, DiBenedetto B, Stoykova A, Boncinelli E, Gruss P, Mallamaci $A$ : Emx2 and Pax6 control regionalization of the pre-neuronogenic cortical primordium. Cereb Cortex 2002, I 2: I29-139.

48. Bishop KM, Rubenstein JL, O'Leary DD: Distinct actions of Emx I, Emx2, and Pax6 in regulating the specification of areas in the developing neocortex. J Neurosci 2002, 22:7627-7638.

49. Schock F, Reischl J, Wimmer E, Taubert H, Purnell BA, Jackle H: Phenotypic suppression of empty spiracles is prevented by buttonhead. Nature 2000, 405:35I-354.

50. Shinozaki K, Miyagi T, Yoshida M, Miyata T, Ogawa M, Aizawa S, Suda $Y$ : Absence of Cajal-Retzius cells and subplate neurons associated with defects of tangential cell migration from ganglionic eminence in EmxI/2 double mutant cerebral cortex. Development 2002, I 29:3479-3492.

51. Soriano P: Generalized lacZ expression with the ROSA26 Cre reporter strain. Nat Genet 1999, 2 I:70-7I.
Publish with Biomed Central and every scientist can read your work free of charge

"BioMed Central will be the most significant development for disseminating the results of biomedical research in our lifetime. "

Sir Paul Nurse, Cancer Research UK

Your research papers will be:

- available free of charge to the entire biomedical community

- peer reviewed and published immediately upon acceptance

- cited in PubMed and archived on PubMed Central

- yours - you keep the copyright

Submit your manuscript here:

http://www.biomedcentral.com/info/publishing_adv.asp
BioMedcentral 